\title{
The Role of Entrepreneurship in the Development of Economies
}

\author{
${ }^{1}$ Bhagavatula Mahesh, ${ }^{2}$ Prof. V. Krishna Mohan \\ ${ }^{I}$ Associate Professor of Management, ABS, Visakhapatnam \\ ${ }^{2}$ Professor in Marketing, DCMS, Andhra University, Visakhapatnam
}

\begin{abstract}
One of the major factors determining economic development is Entrepreneurship. It has been found that the higher the Entrepreneurship in any economy, the greater is the economic development. GEDI is a good indicator of the level of entrepreneurship in any economy. Based on the GEDI it has been seen how developed countries are having a high Global entrepreneurship Development Index. Economies should therefore strive to put a strong emphasis on entrepreneurship as a key to development. In order to achieve this, developing countries should find ways to encourage entrepreneurship and this paper attempts to trace the stages of entrepreneurship development and also suggests measures that can lead an economy to success in this crucial area of development.
\end{abstract}

Keywords: Entrepreneurship, GEDI, Economic growth, development, GEM

\section{Introduction}

It is increasingly observed that there is a strong positive correlation between Entrepreneurship and development of a country. The higher the level of entrepreneurship in a country, the higher is the economic growth, employment, and therefore economic development of a country. The purpose of this paper is to study the correlation between entrepreneurship and development in a country by using data and indexes to establish this relationship.

There are theories which have supported this relation. In his text W.W.Rostow (1960) suggested there countries go through five stages of economic growth. Michael Porter (2002) has provided a modern version of this theory by identifying three stages of development. These three stages are related to entrepreneurship which leads to economic growth. According to Porter, the three stages as identified by him, are factor-driven stage, efficiency-driven stage and an innovation-driven stage. While according to Rostow the emphasis is on age of high mass consumption, Porter's model draws from the recent developments in economics and therefore he emphasizes innovation as a key factor in the entrepreneurial activity. Historically, entrepreneurial class appears to have played a dominant role in innovation and economic growth.

In the factor-driven stage there are high rates of agricultural self-employment. Nations in this stage compete through low-cost efficiencies in the production of commodities or low value-added products. Soleproprietorship or the self employed account for most manufacturing and service firms. Almost all countries experience this stage of economic development. These countries do not create knowledge for innovation and neither do they use knowledge for exporting. The national income is low and mass employment and growth are also low in this stage. India went through this stage during the pre-British period of history. Most of the employment was through agriculture. Handicrafts and potteries were also dominating the economic activities in that era. Understandably there the national income was low and so were the economic growth during that time.

In the efficiency-driven stage, countries must have efficient productive activities in huge markets which allow firms to make use of economies of scale. In this stage there is declining rates of self-employment. The focus is more on capital intensive industries rather than labor intensive industries.

The third stage, which is the innovation-driven stage, is characterized by increase in knowledgeintensive activities. In this stage, knowledge is the main input. The people who possess knowledge become the drivers of the economy. In the innovation-driven stage, there is a bias towards high value-added industries in which entrepreneurial role becomes important.

There is an S-shaped relationship between entrepreneurship and economic growth because in the first stage (factor-driven) entrepreneurship plays a role but it increases at a slow rate as the efficiency stage takes over. But as we move from the efficiency stage to the innovation driven stage, entrepreneurship plays a more important role and it increases at a rapid pace and then the pace decreases. 


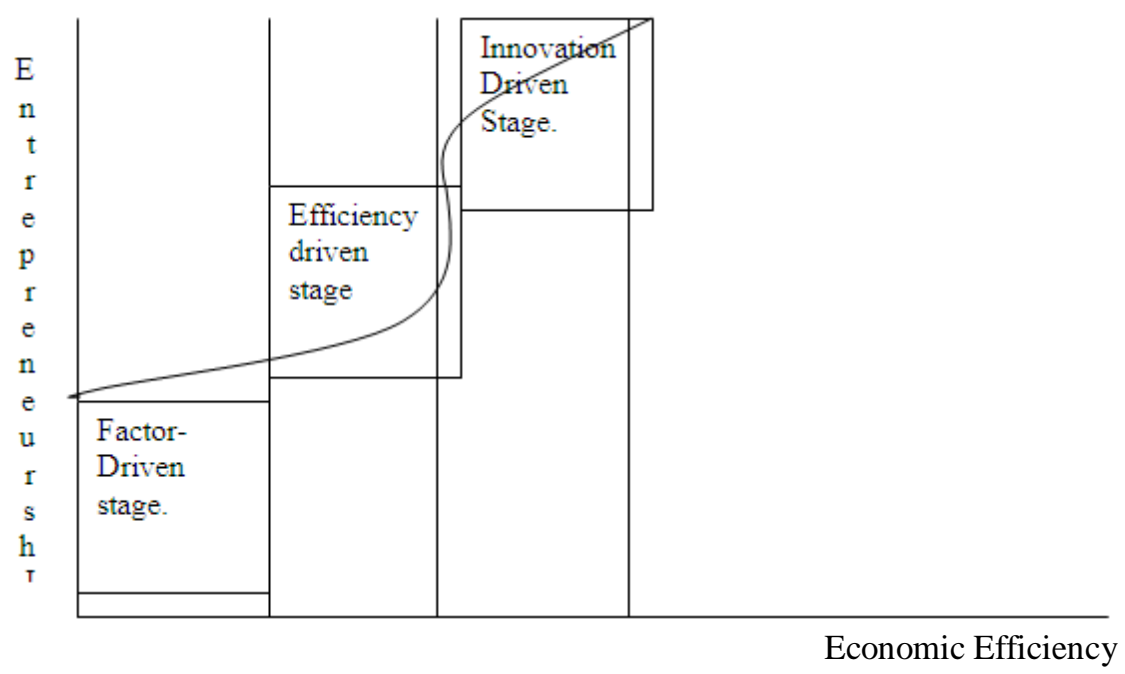

In the above diagram, we can see Entrepreneurship and stages of Economic Growth. As it is clear, in the factor-driven stage, entrepreneurship is low and the economic development is also low. As we move on from the factor-driven stage to the efficiency-driven stage, entrepreneurship increases and so does economic development and in the last stage, i.e. the innovation-stage, entrepreneurship increases and decreases at then flattens.

\section{Objective of the paper:}

The objective of the paper is to measure and compare entrepreneurial activities across countries. An attempt has been made to draw from the Global Entrepreneurship Monitor (GEM) research consortium which has worked to measure and compare entrepreneurial activity. By measuring the entrepreneurial activities based on numerous variables, the paper throws light on the various indicators of entrepreneurship.

The paper however has its own limitations, because the indexes does not provide a comprehensive and exhaustive measure of entrepreneurship, but provides only a part of the picture. Nonetheless, if at the end of the paper, some of the key indicators and how countries can benefit by focusing on these key variables have been identified so that economic development can take place, then the objective is this paper can be said to have been met to a large extent.

\section{Analysis:}

For the purposes of analysis, we have made use of 3 sub indexes which consist of activity, aspiration, and attitudes and these three constitute the entrepreneurship super-index and this is called as Global Entrepreneurship and Development index (GEDI).

The first sub-index, entrepreneurial attitudes are defined as a general inclination of a country's population towards entrepreneurs, entrepreneurship, and startup ventures. Entrepreneurs in this index may be termed as necessity entrepreneurs, as they are formed out of necessity. The index involves measures for the people's perception of opportunity, startup skills, feel of fear of failure, prospects for networking and cultural respect for the entrepreneur. Among the variables that make up the index, the people's opportunity perception is a vital ingredient of start up ventures (Sorenson and Sorenson 2003). Launching of ventures requires the prospective entrepreneur to have the necessary level of startup skill (Papagiannidis and Li 2005). Fear of failure is one of the most important barriers hindering startups (Caliendo, Fossen and Kritikos 2009, Wagner 2002). One of the main reasons of successful entrepreneurship is network. Better networked entrepreneurs are in a better position to identify more viable opportunities and they are more likely to gain access to better resources. Cultural support is also important because without this, even the brightest individuals do not want to become entrepreneurs and may decide to take up some other profession (Davidson, 2004; Guiso et al 2006). Moreover, according to Mueller and Thomas, culture can also influence entrepreneurial potential and personal traits in this regard.

As regards the second sub-index, entrepreneurial activity can be defined a the activity in the medium or high-technology sector initiated by educated entrepreneurs in response to entrepreneurial opportunities in a more competitive environment. They may be termed as opportunity entrepreneurs. The entrepreneurs in this level are better equipped in terms of superior skills and earn more than necessity entrepreneurs (Bhole et al. 2006; Black and Wagner 2006). Operating in high technology sector is important because most of the startups in factordriven countries are largely in traditional sectors and they do not provide high potential for success (Acs and 
Varga 2005). In this sub-index, the entrepreneur's level of education is also an important feature of a venture having high growth potential (Bates 1990). Further, cut-throat competition may curb business survival and growth, so a lower number of competitors improve chances of survival as well as future prospects (Baumol, Litan, and Schramm 2007).

As per the third sub-index, entrepreneurial aspiration may be defined as the efforts of the entrepreneurs to introduce new products and services, develop new production processes, penetrate into global markets, drastically increase the number of employees and finance the business with the help of venture capital etc. Product or process innovation, globalization as well as high growth are also a part of this measure. The three important features of businesses with high growth potential can be considered as Capability to produce new products or creating "new combinations" (Schumpeter 1935), applying or creating new technology and production processes (Acs and Varga 2005). According to findings of empirical studies, it has been seen that only a few businesses say 2-4 \% are instrumental in creation of vast majority of new jobs. Globalization is an important determinant of entrepreneurial aspiration. The availability of risk finance (i.e. equity) can be considered a vital precondition for realizing entrepreneurial aspirations that are beyond the personal financial capacity of individual entrepreneurs.

\subsection{Structure of the Global Entrepreneurship and Development Index:}

The structure of the GEDI consists of 3 sub-indices as detailed above and each sub-index has several pillars. Each pillar consists of an institutional variable and an individual variable. The data values for each variable are collected from various sources.

The pillars (Institutional variables) for the first sub-index ie Entrepreneurial Attitudes consist of pillars, Cultural support, Networking, Non-fear of failure, Startup skills, and opportunity perception. The second subindex, i.e. Entrepreneurial activity consists of pillars Competition, Quality of Human Resources, Technology sector and Opportunity startup and the third and the last sub-index i.e. Entrepreneurial aspirations consists of pillars such as Risk Capital, Globalization, High Growth, New Technology, and New Product.

The GEDI has been constructed for 71 countries which are at different stages of development. The United States ranks third on the GEDI on an overall basis, behind other two countries Denmark at first rank and Canada at second rank.

The table below shows the United State's summary statistics on the three major global ranks and on the GEDI.

Table 1:

Size of Population

Per Capital income

Level of development

Doing Business Index, 2009-2010: rank/total countries

Global Competitive Index, 2008-09: rank/total countries

Economic Freedom Index 2009: rank/total countries

GEDI index: rank (value)

Entrepreneurial attitudes sub-index: rank (value)

Entrepreneurial activity sub-index: rank (value)

Entrepreneurial aspirations sub-index: rank (value)

Weakest Pillar (value)

Weakest variable (value)
308.3 million

$\$ 46,716$

Innovation Driven

$4 / 183$

$2 / 133$

$6 / 179$

$3(0.72)$

$6(0.75)$

$8(0.71)$

$1(0.69)$

Technology sector (0.46)

Knowledge Entrepreneurs (0.30)

Source: Population - World Bank; per capital GDP - World Bank, purchasing power parity;

U.S. Summary statistics and Global Index Rankings - Paper on Global Entrepreneurship and the United States by Zoltan J. Acs, Laszlo Szerb Ruxton, for SBA (Small Business Administration).

From the above table, it is evident that on a global level, the U.S. is highest on Entrepreneurial aspirations which implies that the U.S. has high rating on factors such as introducing new products and services, introducing new production processes, penetrating into global markets etc.

It can also be seen that the weakest pillar is the Technology sector and the weakest variable is knowledge entrepreneurs. Hence, U.S., as a strategy may make efforts to increase its weakest pillar, i.e. the 
Technology sector. This can be done by encouraging entrepreneurs to take up new ventures in the area of technology which can be possible by offering loans at low rates of interest in the technology sector. Banks in the U.S. may not come forward, but the government can initiate action in this by either subsidizing interest or by directly lending through the government machinery. This has to be taken on priority basis, as we know that the financial requirements to undertake such as an activity on a massive scale will be high and it may be beyond the capacity of individual entrepreneurs.

At the individual level, i.e variables for U.S. are knowledge entrepreneurs. As far is this variable is considered, it is imperative that due encouragement be given to knowledge entrepreneurs. It is common knowledge availability of knowledge entrepreneurs will pave way for growth as it will lay the foundation for the establishment of greater number of business units in the area of technology which will fuel the economic development of a nation. Again the government must take a lead from the front in this regard. Establishment of special educational institutions to impart knowledge to budding entrepreneurs will be necessary because it may not be practical or feasible to expect the individuals to gain knowledge on their own. This will require political will and action on the part of the government. But once this is undertaken on a high scale, there is likely to be rise in the growth of Knowledge entrepreneurs and this will further pave way for better quality of entrepreneurs in the U.S.

As regards entrepreneurial aspirations, institutional support is not required, since the U.S. is already on top of the list and it has to sustain its position at this sub index. Entrepreneurial aspirations are related to the social and cultural factors that might be encouraging this zeal among the prospective entrepreneurs. In certain cultures or sub cultures, entrepreneurship may not be seen as a respectable profession and this may be a deterrent factor for promoting entrepreneurship. However, in the U.S., the entrepreneurial aspiration sub index shows that there is no such deterrent and there is a propensity among the entrepreneurs to develop new products and processes, penetrate into global markets, increase the number of employees etc. The phenomenal level of entrepreneurial aspirations is one of the reasons for the development and growth of the U.S. economy.

The GEDI scores of many developed and emerging countries in the world will give a good Indication of the GEDI rank and the economic development of countries.

Table 2 gives the GEDI rankings of all the countries in the data. The United States has a score of 0.72 on the GEDI and occupies the third position in the world out of 71 countries.

Table 2: Global Entrepreneurship and Development Index (GEDI) Rankings

\begin{tabular}{|c|c|c|c|c|c|}
\hline$\overline{\text { Rank }}$ & Country & GEDI Score & Rank & Country & GEDI Score \\
\hline$\overline{1}$ & Denmark & 0.76 & $\overline{36}$ & Argentina & 0.30 \\
\hline 2 & Canada & 0.74 & 37 & Poland & 0.29 \\
\hline 3 & United States & 0.72 & 38 & Croatia & 0.28 \\
\hline 4 & Sweden & 0.69 & 39 & Peru & 0.28 \\
\hline 5 & New Zealand & 0.68 & 40 & China & 0.28 \\
\hline 6 & Ireland & 0.63 & 41 & Colombia & 0.28 \\
\hline 7 & Switzerland & 0.63 & 42 & South Africa & 0.28 \\
\hline 8 & Norway & 0.62 & 43 & Turkey & 0.27 \\
\hline 9 & Iceland & 0.62 & 44 & Mexico & 0.27 \\
\hline 10 & Netherlands & 0.62 & 45 & Dominican Republic & 0.26 \\
\hline 11 & Australia & 0.60 & 46 & Indonesia & 0.26 \\
\hline 12 & Belgium & 0.58 & 47 & Hungary & 0.25 \\
\hline 13 & Finland & 0.56 & 48 & Romania & 0.25 \\
\hline 14 & United Kingdom & 0.56 & 49 & Macedonia & 0.24 \\
\hline 15 & Singapore & 0.56 & 50 & Egypt & 0.24 \\
\hline 16 & Germany & 0.54 & 51 & Jordan & 0.23 \\
\hline 17 & Puerto Rico & 0.54 & 52 & Panama & 0.23 \\
\hline 18 & France & 0.50 & 53 & India & 0.23 \\
\hline 19 & Slovenia & 0.49 & 54 & Brazil & 0.23 \\
\hline 20 & Korea & 0.49 & 55 & Venezuela & 0.22 \\
\hline 21 & Israel & 0.47 & 56 & Thailand & 0.22 \\
\hline 22 & Austria & 0.45 & 57 & Russia & 0.22 \\
\hline 23 & Hong Kong & 0.45 & 58 & Tunisia & 0.22 \\
\hline 24 & United Arab Emirates & 0.42 & 59 & Morocco & 0.22 \\
\hline 25 & Czech Republic & 0.42 & 60 & Jamaica & 0.21 \\
\hline 26 & Chile & 0.41 & 61 & Algeria & 0.19 \\
\hline 27 & Italy & 0.41 & 62 & Serbia & 0.18 \\
\hline 28 & Spain & 0.40 & 63 & Kazakhstan & 0.18 \\
\hline 29 & Japan & 0.40 & 64 & Bosnia and Herzegovina & 0.18 \\
\hline 30 & Saudi Arabia & 0.38 & 65 & Iran & 0.17 \\
\hline 31 & Malaysia & 0.36 & 66 & Ecuador & 0.17 \\
\hline 32 & Latvia & 0.36 & 67 & Bolivia & 0.16 \\
\hline
\end{tabular}




\begin{tabular}{lll|lll}
33 & Portugal & 0.35 & 68 & Syria & 0.16 \\
34 & Greece & 0.32 & 69 & Guatemala & 0.15 \\
35 & Uruguay & 0.30 & 70 & Philippines & 0.13 \\
& & 71 & Uganda & 0.10 \\
\hline
\end{tabular}

Source: Acs, Z. J., and L. Szerb, “The Global Entrepreneurship Index (GEINDEX).” Foundations and Trends in Entrepreneurship 5, no. 5 (2009): 341-435.

Note: Shading indicates countries at the innovation-driven level of development.

The above table shows degrees and in the composition of countries that are seen to outperform the United States. As regards the rankings of U.S. on the GEDI and the sub-indexes, the position of U.S. is at the top of the curve. However, the position of U.S. on entrepreneurial activity sub-index is low relative to other high performing countries. In entrepreneurial aspiration sub-index, the U.S. occupies the top rank which shows that within the U.S., there is a dramatic effort on the part of early entrepreneurs to introduce new products and service, production processes, penetrate into world markets and to create high growth enterprises.

On Entrepreneurial-Attitudes sub-index, the US. Ranks 6, below Australia, New Zealand and Canada and two other countries, but its performance is much better when compared with most European countries barring Sweden and Denmark. On entrepreneurial activity sub-index, the U.S. is ranked at a relatively low rank i.e. 8 and is a cause for concern. This shows that during the last decade the US may have lagged behind in terms of opportunity startups and quality workforce as well as the activities in the technology sector.

The values and data show very interesting trends in attitudes, activities and aspirations.

\subsection{Policy Approaches:}

The study of the GEDI index has many ramifications. It enables the countries to adopt policies which are relevant to encourage sub-indexes properly so that the developing nations can embark on a development plane. Before suggesting the policy approaches, we must understand that al the three entrepreneurial subindexes are not of equal importance. The attitude sub-index measures society's basic attitude towards entrepreneurship which can be enhanced through higher education and social stability. The activity sub-index indicates what individuals are doing to improve the quality of human resource and technological efficiency. The aspiration sub-index shows ho much of the entrepreneurial activity is directed towards innovation, high growth entrepreneurship and globalization.

The sequence of the sub-indexes is also important. Attitudes are necessary prerequisite for activity or aspiration. Attitude is followed by activity and this is followed by aspirations. It needs to be understood that in an agricultural economy the emphasis should be on entrepreneurial attitudes in the people. In an efficiencydriven economy ie. In a Manufacturing economy, individuals need to be motivated to become entrepreneurs and to start businesses. In the innovation-driven country, ie knowledge-based economy, some people need to create large and successful enterprises.

\subsection{Implications for developing countries (Special reference to India):}

It can be seen from the GEDI rankings that the first top 16 countries are highly developed economies and their GEDI scores are ranging from $0.54\left(16^{\text {th }} \mathrm{rank}\right)$ to $0.76\left(1^{\text {st }} \mathrm{rank}\right)$. The first position is Denmark and the $16^{\text {th }}$ position is Germany. This indicates a positive correlation between GEDI scores and the level of development. It also shows that these countries are at the innovation-driven level which is the third and last stage of the three stages of development as conceptualized by Michael Porter.

The position of developed countries on the sub-indexes is also an important indicator. Those countries which are scoring high on the sub indexes are also a strong indicator of development. Hence the developing countries should take a cue from these indicators and attempt to increase thrust in those sub indexes which ultimately lead to growth.

India, for instance was till recently an agricultural economy and around $70 \%$ of the population was engaged in agricultural activities. Therefore the economic growth in the 1960s and 70's was low. Now, however, India is one of the fastest developing economies of the world and there has been a sea change in the attitudes of people towards entrepreneurship. India can now be considered a manufacturing economy, and therefore the Indian government needs to motivate individuals to become entrepreneurs.

The Government of India realized that in order to develop its economy it had to take drastic measures to raise the level of entrepreneurship in the country. The gains were seen and in order to consolidate on these strengths and to take initiatives to prepare Indian industry to respond effectively to the emerging challenges the government of India initiated a number of policy and procedural changes which were introduced in 1985 and 1986 aimed at increasing productivity, reducing costs and improving quality. The focus was on opening the domestic market to increased competition and readying our industry to stand on its own in the face of international competition. Earlier the public sector was having many constraints but it was freed from a number 
of constraints and given a greater autonomy. The technological and managerial modernization of industry was pursued as the key instrument for increasing productivity and improving our competitiveness in the world. The net result of all these changes was that Indian industry grew by an impressive average annual growth rate of $8.5 \%$ in the Seventh Plan period.

Though the economic growth in the recent past has been impressive, it needs to implement microeconomic policies that foster entrepreneurial activities that ultimately fuel economic growth. In recent years, India has made several structural changes that include building a wide telecommunication network and launching a nation wide road construction program. But these are not enough. Recent studies the world over suggest that the cultural characteristics that can help the encouragement of entrepreneurial activities include a strong educational base, financial support, opportunities for networking among entrepreneurs etc. The Government needs to make serious efforts to strengthen these areas.

Further, It has been seen that though India has a strong manufacturing base and as stated above, it can now be considered a manufacturing economy, it needs to reexamine its export strategy since it is generally inferred that a country's economic growth prospects is affected by its exports structure. Presently it is exporting low -technology products such as textiles, plastics. Developed economies in the world export products in hightechnology areas. India, with its extraordinary talent pool may have to enter into fields such as complex electronic machinery, precision instruments, high end automobiles etc for it to have a competitive advantage in the field of high growth export areas.

3.4 Franchising: Franchising can be considered an important weapon to encourage entrepreneurship One of the major advantages that it offers to budding entrepreneurs is that it attempts to mitigate risk of an entrepreneur. Risk bearing is one of the major deterrents of entrepreneurship. If the risk element is reduced, there will be more individuals who would venture out into business start ups. Ordinary business start ups face a major problem as regards to evaluation of an opportunity, finding the right location, finding the right product, establishing the brand etc. The franchise model acts as a win-win situation to both the franchisor and the franchisee. The franchisee benefits from a time tested and proved business concept. There are several successful business establishments that are making use of the Franchising option to spread their wings all over the world. Some of the well known and world renowned franchisors are McDonalds, Pizza hut, KFC, etc. This industry is growing at a very fast rate at $25-30 \%$ and is the second fastest growing industry. In India, franchising industry is in its nascent stage. But it has huge potential since the middle class segment of the Indian population is growing. Today, 33 million Indians can afford the best goods and services and 310 million Indians buy consumer electronics. According to WTO guidelines the service sector will bring in more opportunities for the Indian entrepreneur and a larger market for the franchising. With Goldman Sachs predicting that India will be the third largest economy in 2025 and S\&P upgrading India's credit standard, and an extremely stable government, the franchising community will be headed towards fast development.

\section{Conclusion:}

In conclusion, we may state that the GEDI index which shows the rankings of nations in Entrepreneurship is a valuable indicator for policy makers throughout the world since it also shows that the nations which rank high on the GEDI index are economically developed nations. All nations can generate substantial economic gains by pursuing policies that encourage Entrepreneurial activities.

The countries need to understand the stages of entrepreneurial activity that they are in and also the measures they need to take at the appropriate stage. The sub -indexes provide these guidelines.

It is also recommended that countries should pursue those activities that aim at producing hightechnology and high value goods and services so that economic growth takes place in a rapid manner.

Things do not happen by a sleight of a hand. Entrepreneurial activities of this kind can take place if the Governments of various developing and emerging nations take proactive measures to encourage these activities. Farsighted and bold measure need to be adopted and implemented if rapid Economic growth has to take place the entrepreneurial way.

\section{References:}

[1]. Acs, Z. J., and L. Szerb, ((2009) )“The Global Entrepreneurship Index (GEINDEX).” Foundations and Trends in Entrepreneurship 5, no. 5): 341-435.

[2]. Dhawal Shah, Entrepreneurship, opportunity, franchising

[3]. Joseph Schumpeter, (1934), "The Theory of Economic Development"

[4]. Anil K. Lal, and Ronald W. Clement (Dec 2005), "Economic Development in India: The Role of individual Enterprise (And Entrepreneurial spirit)", Vol. 12, No. $2:(9-22)$

Keywords: Entrepreneurship, Innovation, Economic Growth, Franchising, GEDI rankings, Policy. 